\title{
Research Infrastructure Megaproject (RIMPS) management in an ecosystem perspective Literature Review
}

\author{
Teodora Marinova Georgieva \\ International Business School, \\ Sofia, Bulgaria \\ tgeorgieva@ibsedu.bg
}

DOI 10.5592/otmcj.2012.3.6

Keywords

MEGAPROJECTS management, research infrastructure, ecosystem perspective

AS THE ECONOMIC, TECHNOLOGICAL AND SOCIAL CHALLENGES OF CREATING NATIONAL AND REGIONAL COMPETITIVENESS HAVE BECOME INCREASINGLY DIFFICULT TO ADDRESS IN A VALUABLE WAY, GROWTH-FRIENDLY FACTORS LIKE RESEARCH INFRASTRUCTURE NEED TO BE EXPLOITED IN THEIR FULL CAPACITY AND CAPABILITIES.

This paper outlines the principal characteristics of MEGAPROJECTS in the field of research infrastructure in an ecosystem perspective. The paper is considered to be an empirically informing positioning paper that seeks to encapsulate the success factors required for RIMPs. The analysis of the RIMPS is based on A RANGE OF METHODS (deduction, synthesis, case study analysis; systemic and holistic approaches) used in order to address the issues under examination.

The paper discusses the role of research infrastructure megaprojects for creating the European Research Area and boosting the innovation potential of the European economy. The well-defined profile of RIMPs with clear understanding of their specific characteristics, considered within the ecosystem framework, are the most important precondition for successful project management. RESEARCH LIMITATIONS in this paper are predetermined by the lack of comprehensive analyses in the field of RIs, comparing different practices and national models and discussing the challenges for their effective management.

\section{Introduction}

The question "Is innovation-led growth now the only option?" (Goodridge et al., 2012) is becoming urgent for an increasing number of economies in a post-crisis time. In all its strategic and visionary documents (framework programmes, Lisbon Strategy, Europe 2020, etc.) the
EU considers science and innovations to be of prime importance for the European economy not only in order to close the gap with main competitors like USA, Japan, South Korea, etc., regarding indicators on innovation performance but also with the aim to create unique sources of knowledge-based competitiveness. 
Despite the progress achieved during the last decade in terms of R\&D expenditures in the public sector as \% of GDP, including EU funding [1] Europe still remains well behind world innovation leaders in the fields of "Open, excellent and attractive research systems" and "Linkages and Entrepreneurships".

Research infrastructure (RI) is of crucial importance for achieving scientific breakthroughs, technology advancement and knowledge transfer and as such it is a key milestone in the European research agenda and innovation policy. That is why $R \mathbf{I}$ is put at the heart of the "knowledge triangle" [2] as a facilitator of the network between research, education and innovation. Research infrastructure, along with the human capital concentrated around it, is recognised as a prerequisite for excellence in science, an enabler for industrial application of scientific results and a way to address the weaknesses in science and innovation policy coordination and networking at the European level.

Across the European Union a considerable potential is built in terms of research centres and facilities or science and technology parks which serve as hubs for creating knowledge and transferring it into innovation results (radically new and improved processes, products and services). However, together with that, and especially in times of crisis and need for restriction the European research community is facing a number of challenges among which are: > The process of designing, constructing, operating and sharing complex research infrastructures is a serious dare for every economy. Furthermore, the requirements for efficient project implementation in time and to budget have increased over the last years.

- Despite the considerable efforts made through European programme instruments, the European Research Area still remains fragmented and imbalanced in regard to particular scientific fields and world class research facilities. An integral approach to research is needed in order to ensure easy access to leading research centres for national scientific communities and intensive circulation of data, information, knowledge and technologies across them.

- The strong European positions in science and research do not correspond to the delay in the adoption and dissemination of the results received. Entrepreneurship and the spirit of innovation are weaker in Europe than in some well-developed (USA, Japan) and fast-developing (South Coria, China, India) countries. This diminishes the rate of return of public investments and, consequently, the level of social recognition of the role of science in addressing contemporary social, economic and environmental problems.

Together with the variety of political measures, the effective governance of large-scale usually shared complex research infrastructure projects can be described as a successful tackling of the challenges mentioned above. There are a range of sources (international standards, EU official statements, research studies and analyses) concerning the matter of project management, or research infrastructure taken alone. However, it is a quite recent practice to address problems associated with complex project management in the field of research infrastructure.

This paper is intended to build upon the research agenda for effective management of megaprojects focusing on the research infrastructure as a specific field for their implementation.

The importance given to modern complex research infrastructures and the objectives pursued by their construction, including:

a) increased research capacity for addressing contemporary social and environmental problems,

b) ensured access for remote science communities, as well as

c) developing a common platform for more intensive networking, inter- action and transfer of ideas and research results at a multidisciplinary base

are sufficient grounds for application of a new holistic approach comprising existing theoretical statements and practices in order to give answers to the questions as follows:

Which are the main specific features of the complex research infrastructures complementing and enriching the well-known characteristics of megaprojects as an object of management practices?

- How can the RIMPs be described in an ecosystem perspective and how can we define the scope of the RIMPs ecosystem?

Which are the most crucial factors influencing the successful management of RIMPs and how can we cash in on them in order to achieve a higher level of effectiveness?

A database is created gathering information from the European portal on Research Infrastructure' services [3] with the main indicators concerning the type, location, scientific domain, activities, initial investments, operational costs, etc. of every one of the all 625 unique Research Infrastructures presented there. The database is not exhaustive, but nevertheless can be considered as representative for the current national and European practises of constructing and operating Research Infrastructures. Data have been further processed in order to provide detailed characteristics of the most known RIs typology - single-sited, dispersed and/ or virtual (See Table 2 below). The location of RIs' facilities (i.e. the presence within one or different national innovation ecosystems) is the most important factor influencing the intensiveness of information flows, the management practices put into place and the effectiveness of the decision making process. As a result the above mentioned groups have been chosen as a base for the following analysis.

A combination of the following meth- 
Horizon 2020

(2014-2020) [5]

$2010[6]$
Horizon 2020 is focusing on three priorities, the first of which is Excellent Science, including world-class research infrastructure accessible to all research in Europe and beyond. The indicative direct budget to European research infrastructure (including e-Infrastructure) is $2.478 \mathrm{M} €$ which is $3 \%$ of the whole Horizon 2020 budget and $10 \%$ of the budget of the first priority.
$2009[7]$

$\mathrm{FP7}$

(2007-2013) [8]

$2007[9]$

$2006[10]$
The Europe 2020 Strategy's flagship initiative Innovation Union pointed out the target to complete or launch the construction of $60 \%$ of the priority European research infrastructures identified by the ESFRI to 2015 .
European Commission proposed a legal framework for a European Research Infrastructure Consortium (ERIC) adapted to the needs of such facilities. Its adoption ensured the existence of an easy-to-use legal instrument providing the spirit of a truly European venture; legal personality recognized in all EU Member States; flexibility to adapt to the specific requirements of each infrastructure; some privileges/ exemptions allowed for intergovernmental organisations; a faster and more cost efficient process than creating an international organisation.
1.700 M€ for research infrastructure under the Capacity programme. Indirect support from other FP7 programmes such as People and Ideas complement the use of RIs.

Promote coherent use and development of existing RIs and facilitate the construction of new panEuropean RIs, or major upgrades of existing ones.

The Green Paper on "The European Research Area: New Perspectives" argues that there is an urgent need to revisit the European Research Area (ERA) and puts questions to the EU institutions, Member States, regions and stakeholders.

2003 [11] The e-Infrastructure Reflection Group (e-IRG) was set up with the main objective to provide support at the political, advisory and monitoring levels, to help with the creation of a policy and administrative framework for the easy and cost-effective shared use of electronic resources in Europe.

$2002[12]$

ESFRI produced the first ever European Roadmap for Research Infrastructures for new and upgraded large-scale RIs. The aims are to identify new research infrastructures or major upgrades which correspond to the needs of European research communities, to provide a tool for decision makers, preventing over-provision of facilities in particular areas, to provide a focus for long term budgetary planning by funding actors.

the European Commission in order to jointly reflect on the development of strategic policies for pan-
European Research Infrastructures, to prepare a European Roadmap (with regular updates as different
areas mature), to act as an incubator for RI projects with pan-European interest.

FP6

(2002-2006) [13]

2000 [14] The idea of a common European Research Area (ERA) was launched. The central role of RIs was

$715 \mathrm{M} €$ for research infrastructure.

Promote coherent use and development of existing RIs and facilitate the construction of new pan-European RIs, or major upgrades of existing ones. emphasized in order to ensure the progress and application of knowledge across Europe. and dynamic knowledge-based economy in the world, capable of sustainable economic growth with more and better jobs and greater social cohesion.

$\mathrm{FP}_{5}$

(1998-2002) [16]
Support for research infrastructures was directed to ensure an optimum use of existing research infrastructures; and, transnational cooperation in the rational and cost-effective development of research infrastructures in line with the objectives of the thematic programmes, as well as to enhance access to infrastructures and in particular for research infrastructure networks leading to further complementarity, pooling of efforts and/or specialization at the EU level.

$$
\begin{aligned}
& \text { FP4 } \\
& (1994-1998)[17]
\end{aligned}
$$

The essential objective of the "Access to Large-scale Facilities" (LSF) Activity of the Training and Mobility of Researchers (TMR) Programme is to provide scientists and engineers from any of the Member States of the Community, and the states associated to the Programme (Iceland, Israel, Liechtenstein and Norway) with access to Europe's large-scale research facilities. 


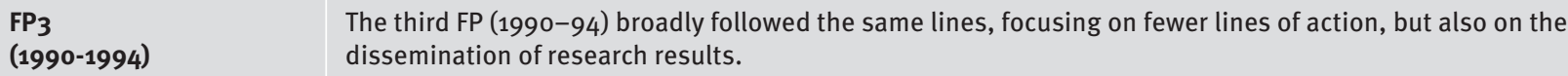

$\mathrm{FP}_{2}$

(1987-1991)

The main aim of the second FP (1987-91) was to develop technologies for the future, integrating major Community programmes in the areas of information technology (Esprit), materials (EURAM), industrial technologies (BRITE) and advanced communications technologies (RACE).

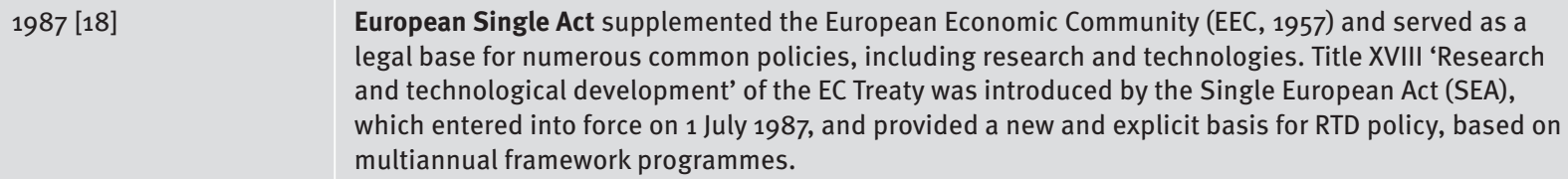
legal base for numerous common policies, including research and technologies. Title XVIII 'Research and technological development' of the EC Treaty was introduced by the Single European Act (SEA), which entered into force on 1 July 1987, and provided a new and explicit basis for RTD policy, based on multiannual framework programmes.

FP1 (1984-1987) Community RTD activities were for the first time coordinated as part of a single, structured framework.

$1983[19]$

European Strategic Program on Research in Information Technology (ESPRIT) was established as a series of integrated programmes of information technology research and development projects and industrial technology transfer measures. It was a European Union initiative managed by the Directorate General for Industry (DG III) of the European Commission. Five ESPRIT programmes (ESPRIT o to ESPRIT 4) ran consecutively from 1983 to 1998.

$1957[18]$

The Treaty of Rome established the European Atomic Energy Community (Euratom) a key element of which was to coordinate of the Member States' research programmes and a joint research programme, implemented in a Joint Research Centre (Articles 4 to 11).

Table 1 Research infrastructures as a subject of high level discussions and reflections across EU -RI(M)P's timeline

ods has been used to achieve the objectives of the research: 1). Analysis of statutory and other documents of public policies related to provisions pertaining to infrastructure at local, national and European level with the aim of defining objective conditions within which research infrastructures, key stakeholders in respect to their establishment and functioning, as well as interaction may be defined; 2). Case-study including collection and analysis of varied quantitative and qualitative data about the functioning of different types of research infrastructures and the established practices for their management as special types of projects; 3). Statistical methods of analysis of quantitative data, including with the help of the software for statistical analysis SPSS. The combination of different methods is exceedingly important as it permits the comparison of data collected from different sources. This allows to 'fill in the blanks' in the studied field and to improve the opportunities for interpreting the data.

\section{Research infrastructure in the EU agenda for knowledge based growth and competitiveness}

Research infrastructure (RI) is of prime importance for bringing into practice of the objectives of EU policy in the field of science, technology and innovation. RI(M)Ps have a large proportion of EU funds on the development of scientific and innovation potential. Given its importance, $\mathrm{RI}$ is made a priority in various EU funding instruments (mostly through framework programmes), policy documents (ESPRIT, Lisbon Strategy, ERIC, Europe 2020, etc.) and strategic roadmaps (OECD provided a Report on roadmapping of large research infrastructures where 20 roadmap exercises are mentioned [4]) (see Table
1). The common aim of these European initiatives is to boost construction and operation of world-class RIs, optimise the exploitation of existing research assets at a pan-European level, balance the research-innovation objectives in a short- and long-term, and augment the socio-economic impact as a result of RI(M)Ps governance.

Although terms describing research infrastructures like science, research, technology, innovation, etc., are more fuzzy than strictly defined, there exist definitions which can be used as a starting point for distinguishing the main specific characteristics of RIs as a particular case of the most common meaning of the term "infrastructure project".

An exhaustive definition of the term was given for the purposes of $\mathrm{FP}_{5}$ where it was said that "research infrastructures" refer to facilities and establishments that provide a world-class service essential for the conduct of top quality 
research - rare in Europe - which has investment or operating costs that are relatively high in relation to those costs in its particular field, and which is able to provide adequate scientific, technical and logistic support to external, particularly first-time, users. It covers, for example, singular large-scale research installations, collections, special habitats, libraries, databases, integrated arrays of small research installations, as well as infrastructural centres of competence. [20]

The overwhelming majority of the later ERA related documents describe research infrastructure in a way cor- responding with the definition given to the need of the Community Framework Programme for research and technological development, namely "facilities, resources or services that are needed by the research community to conduct research in all scientific and technological fields, including: major equipment

\begin{tabular}{|l|l|l|}
\hline Criteria & Single-sited RIs & Distributed RIs \\
\hline Patterns & $\begin{array}{l}\text { Libraries, Satellite and } \\
\text { aircraft observation facilities, } \\
\text { Observatories, Telescopes, } \\
\text { Synchrotrons, Accelerators, } \\
\text { Science and technology parks, etc. }\end{array}$ & $\begin{array}{l}\text { Grid computing, Research centres, } \\
\text { laboratories and other facilities, } \\
\text { located at different places but } \\
\text { working on the base of a common } \\
\text { platform as part of a whole } \\
\text { structure }\end{array}$ \\
\hline $\begin{array}{l}\text { Role within } \\
\text { the research } \\
\text { and innovation } \\
\text { ecosystem }\end{array}$ & $\begin{array}{l}\text { Create innovation and } \\
\text { entrepreneurial culture, } \\
\text { intermediary services, Intensive } \\
\text { technology transfer }\end{array}$ & $\begin{array}{l}\text { Develop research capacity of more } \\
\text { than one research institutions, } \\
\text { Address common problem areas, } \\
\text { Boost interaction between the } \\
\text { organizations involved in R\&D } \\
\text { process and along the innovation } \\
\text { chain }\end{array}$
\end{tabular}

Virtual RIs

Collections, Archives, Structured information, Databases, Depositories, Public Repositories, Communication networks, etc. electronically accessible for remote science communities

Enable the establishment of virtual research environments, Promote world-wide access to e-Rls

\begin{tabular}{l|l}
$\begin{array}{l}\text { Main project } \\
\text { results }\end{array}$ & $\begin{array}{l}\text { Smart specialisation, Regions/ } \\
\text { clusters of knowledge, Knowledge } \\
\text { hubs, gathering of critical mass }\end{array}$
\end{tabular}
hubs, gathering of critical mass
Development of a shared RI, Open access to researchers and students, Extended research collaboration and activities, Extended R\&D efforts

\section{Social and} economic reflections

\section{Overcome economic and social} disparities, Local spin-offs and start-ups, New directly and indirectly created jobs
Joint R\&D projects with business, Effective use of shared facilities, Increased social cohesion
Research collaborations, Synergy effects, Knowledge exchange

\begin{tabular}{|l|l|l|l|l}
$\begin{array}{l}\text { Sources of } \\
\text { uncertainty }\end{array}$ & $\begin{array}{l}\text { Lack of administrative capacity, } \\
\text { Lack of management expertise }\end{array}$ & $\begin{array}{l}\text { Lack of standardisation both } \\
\text { in management procedures } \\
\text { and technologies used, } \\
\text { Strategy misunderstandings/ } \\
\text { disagreements }\end{array}$ \\
\end{tabular}

Project

management practices
Multi-functionality, Vertical organisational structure, Concentration of competencies
Shared responsibility, Coordination
Ensure fast dissemination of the results and their transfer in innovative products
Technical bottlenecks, Lack of adequate support, Access restrictions, Unauthorised access, Accessible to cyber attacks

Virtual management, Low-cost due to the lack of tangible assets, Extensive use of ICT as an accelerator of information flows, Coordination and functionalities

Examples

CERN,

European Northern Observatory

ENO,

International experimental fusion

reactor ITER,

British Library
European ocean observing system Euro-ARGO

European Mouse Mutant Archive EMMA,

International EGEE GRID

computing facility

Planned European Extreme Light

Infrastructure ELI
Pan-European high speed, high capacity communication network GEANT,

European Social Survey ESS,

European Bioinformatics Institute (EBI),

International Medieval

Bibliography 
ITC, Mathematics

Engineering

Material Sciences, Chemistry and Physics and

Astronomy

Life Sciences

Energy

Environment, Marine and Earth Sciences

Socio-economic Sciences

Humanitites and Behavioural Sciences

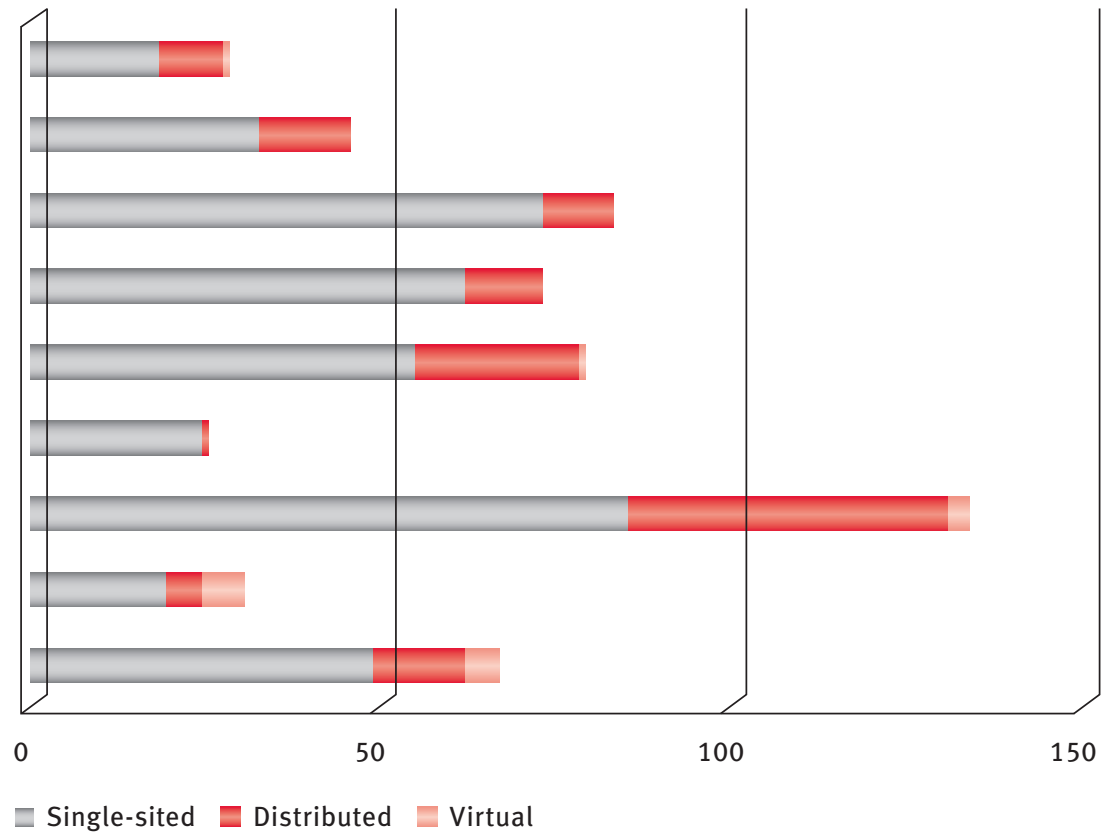

Figure 1 Research Infrastructures by location and main scientific domain, number

or set of instruments used for research purposes, knowledge-based resources, enabling ICT-based infrastructures and any other entity of a unique nature that is used for scientific research along with associated human resources". [21] (see Table 2)

Within the European database 625 unique Research Infrastructures are registered. Most of them (almost 76\%) are low-scale infrastructures (273 of them are built with an initial investment fewer than 20 million of euro, and 123 are built with an initial investment in a range between 20 and 50 million of euro). The large-scale infrastructures (with an initial investment in a range between 250 and 500 million of euro) account for just over $4 \%$. Approximately $\mathbf{7 4 \%}$ of RIs are single-sited. Providers of only virtual services are $3 \%$ of facilities, but a great number of single-sited and distributed RIs ensure virtual access to a part of their products/services at a contractual base.

The largest group of RIs is in the field of Environment, Marine and Earth Sciences ( $24 \%$ ), followed by Material Sciences, Chemistry and Nanotechnolo-

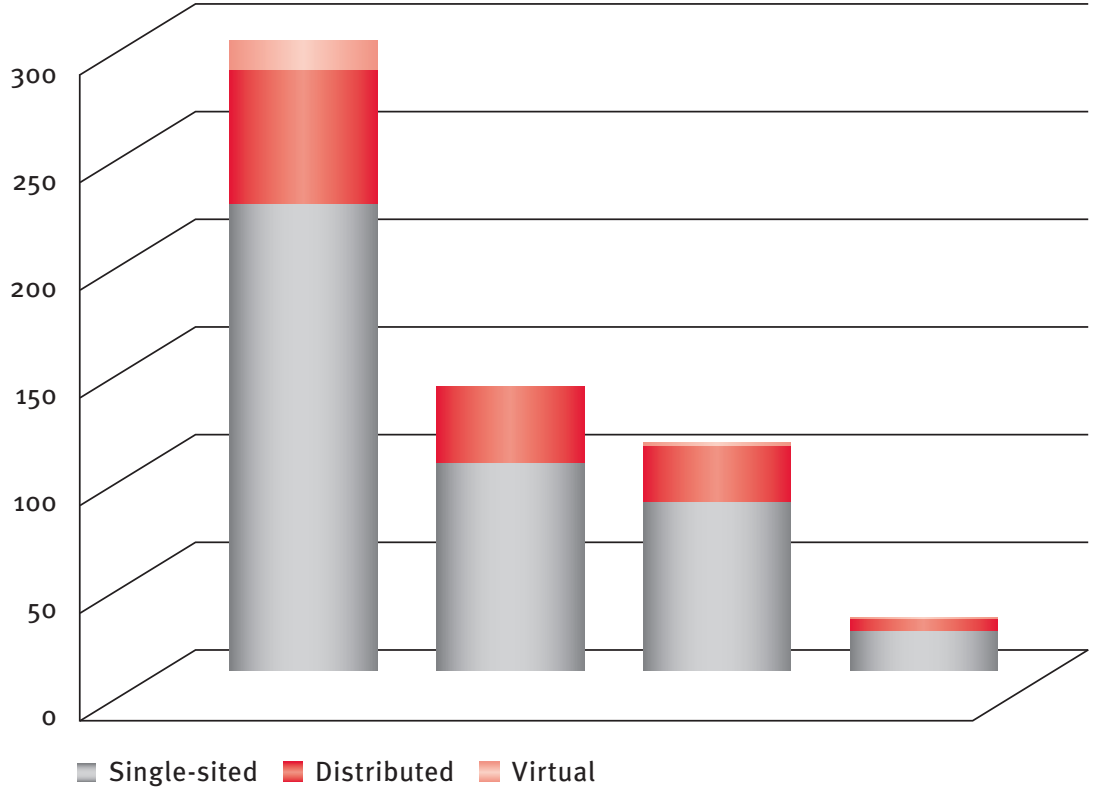

Figure 2 Research Infrastructures by location and scope, number

gies (15\%) and Life Sciences (14\%). Within the different scientific domains the greatest internal dispersion in terms of scale exists in the field of Socio-economic Sciences where $97 \%$ of RIs are built with an initial investment fewer than 50 million of euro. There is a lack of large-scale RIs related to this scien- tific field. The most balanced in terms of scale is the group of RIs in the field of Energy. Figure 1 / Figure 2

In particular, large-scale research infrastructures are defined as "those facilities with many or all of the features as: large research capacity, trans-national relevance, requiring sizeable in- 
vestment and, generally, having high operating costs, with unique or rare character and a consequential impact on science and research at both the global and European level" [2]. Thereby the "project triangle" of megaprojects (scope-cost-time) relative to largescale research infrastructures can be interpreted as follow:

> size (scope/scale) - RIMPs are designed in a way allowing multi-functionality and multi-disciplinary in order to provide services to a diverse number of stakeholders and, consequently, to cope with complex problems of contemporary society. Often RIs are deployed at remote locations which create high levels of risk and uncertainty, or include so called "support infrastructure” (Favali, 2009).

> investment and operating costs - the typical for megaprojects EUR 0.5 billion [22] of investments are extremely exceeded in the case of RIMPs especially when an entirely new infrastructure is constructed. RIMPs are a combination of long-term investment and stable high whole-life operating costs directed to a result with vague parameters due to the creative character of R\&D-activity. Serving more societal than business interests RIMPs are an object mostly to public (usually trough EU programme instruments) and less to private financing. The serious amount of investments needed for RIMPs implementation implies shared contribution by a number of countries/organisations.

duration - according to the "standard" definition of megaprojects RIMPs accumulate enormous resources in terms of investments and human capital and need considerable time for realisation. What is specific for RIMPs is that in many cases they include an extensive preparatory phase (see Box 1.) during which processes like finalisation of construction plans, legal organisation, financial engineering and some management aspects are in progress (Spurio, 2012).
In addition to the above mentioned features making megaprojects clearly recognizable, the International Centre for Complex Project Management added in its Research and Innovation Strategy two extra ones [23]: a) need for negotiating diverse and emerging issues in dynamic and changing economic, social and environment contexts; and b) significant implications for the society - both valid for the research infrastructures.
While bearing all of the above in mind, it is necessary to add some specific aspects concerning research infrastructure as a particular object of interest for project management:

1. The understanding of the nature of the complexity associated with RI(M) Ps is an important precondition for their effective management. The high level of complexity embedded in all research infrastructure projects (not only large-scale ones) de-

\section{Box 1. Technology park implementation: Preparatory phase's value chain}

A preparatory phase of a project for establishing of a science and technology park could comprise:

1). Business Planning and Business Development. A Business Plan for the Scientific and Technology Park project is required in order to present details of the development of the site; the structure of the project development team; the sector and research focus; infrastructure requirements and financial profiling. The Business Plan may include: executive summary, business/investment opportunity, industry overview, Science and Technology park Description and strategy, management summary and financial projection, site details, construction quotations, potential tenants and industry surveys, etc.

2). Site Selection. On the basis of previously selected criteria (e.g. site size, land ownership, zoning/planning/stakeholder, physical attributes, accessibility, utilities, location, site development costs/time) and detailed information the suggested sites are assessed and a decision is made about which of them meets at a higher level the requirements for establishing the Scientific and Technology Park.

3). Beneficiary Capacity and Capability. The competencies of the project beneficiary are described as a fundamental requirement of the project development process and a factor to secure pre-financing and financing for the Scientific and Technology Park project. The identification and assessment of capacity and capability of the project beneficiary (direct beneficiary as an exception) is a subject of an extended review.

4). Project Application to the Operational Programme/funding body/instrument. The project application process is based upon the information provided with the Business Plan. Depending on the submission of the project application a contract is established between the beneficiary and the operational programme/funding body.

5). State Aid Notification. The Science and Technology Park is considered to have elements of aid in relation to the project beneficiary (market failure, profitability), land transfer to the beneficiary and the aid to technology park tenants. In this respect the project team has to formalise the State Aid Notification application for submission to the European Commission.

6). Master Planning. The Master Planning represents the first phase in the development of the site. The Master Planning consists of three phases: prequalification, tendering (tender specification and tender review process followed by the appointment of suitable organisations) and master plan completion.

The successful implementation of this first preparatory phase is a precondition for the next step - improvement of the preparation of the major project under requirements of the financing body, establishment of the scientific and technology park and strengthening the research capacity in a long-term. 


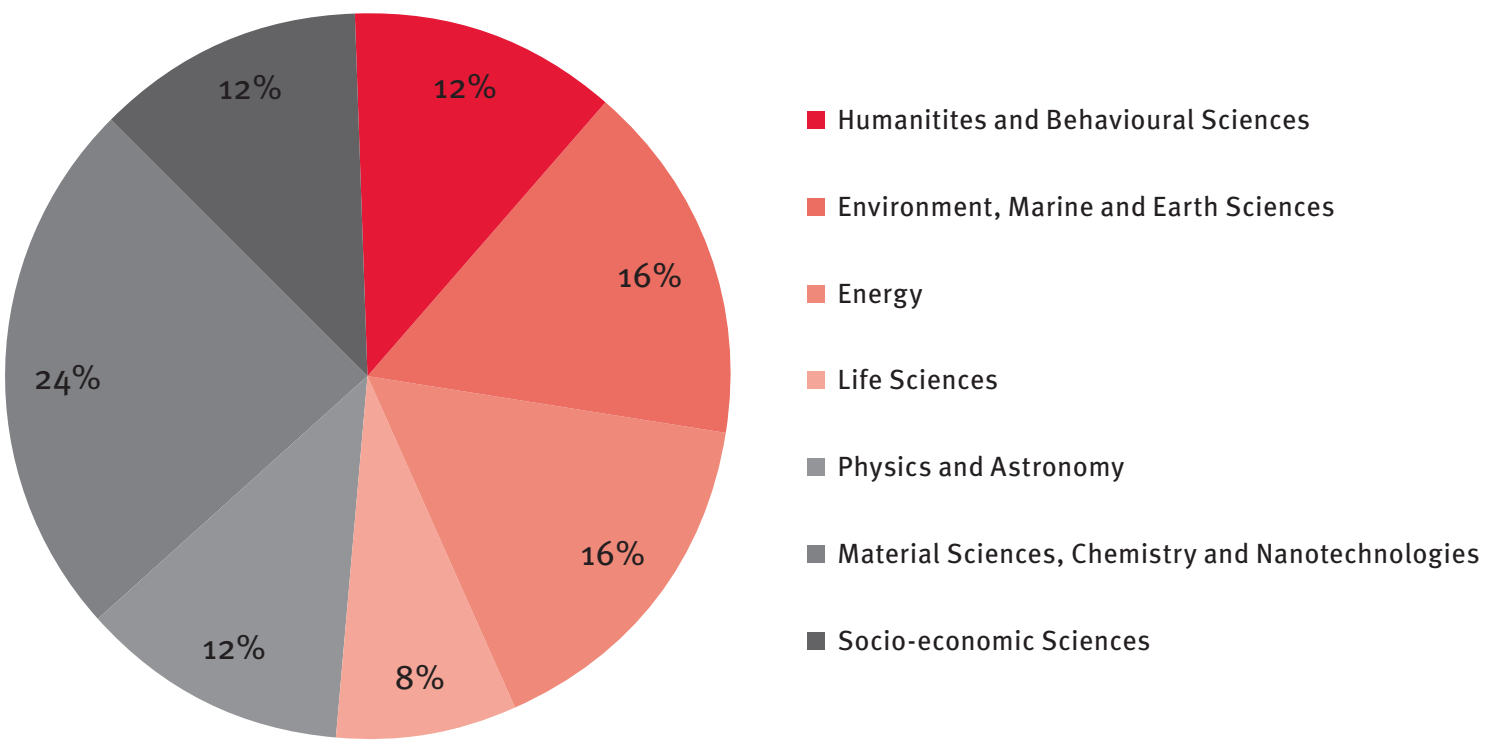

Figure 3 Research Infrastructures Megaprojects by main scientific domain, \%

rives from sources which are difficult to be included in the standard project management framework because of their creative nature (i.e. impossible to foresee in terms of the expected results), variability in regard to the set and number of stakeholders engaged at the construction and post-construction phase when the research infrastructure is under use (science communities from different countries and with different culture), and multi-functionality which creates real obstacles associated to the process of monitoring, measuring and controlling the outcomes.

Like megaprojects in the fields of transport infrastructure (highways, tunnels, bridges, railways, seaports), energy sector (conventional, nuclear or renewable power plants, oil and gas extraction and processing projects), etc., RIMPs can be implemented through establishing of entirely new facilities or improvement of existing ones. However, there is an additional approach related to the integration of tangible and intangible assets, competencies and functions of existing research centres and conducting of them as parts of a common structure and in achieving a shared strategy. The Eu- ropean Carbon dioxide Capture and Storage Laboratory Infrastructure (ECCSEL), whose mission is to form a pan-European integrated RI of Centres to build and operate new CCS R\&D infrastructures, can be pointed out as a good practice (Gronli et al., 2011).

2. RIMPs have primarily a non-for-profit orientation. This is due to the profile of the stakeholders involved (researchers, research institutions, universities, intermediaries, etc.), the activities implemented by using RIs (scientific research, ideas generation, technology development; technical expertise, etc.), and the objectives pursued (concerning sustainable development in its main dimensions: societal, economic and environmental, in a longterm prospective).

Moreover, the financial resources invested in research infrastructures are part of the EU budget accumulated by member states' shares and do not originate from private sources. Consequently, they are used in a way allowing the contemporary challenges at EU level to be addressed and/or a wider access to the effects gained to be ensured.

3. An extremely high level of networking and virtuality is associated with
RIMPs. It is a result of the fact the science community, which is the main stakeholder in the projects, comprise researchers, research centres and universities located worldwide and using primarily remote access to research facilities. Information and communication technologies and the dynamic trends for their development are, of course, the preconditions which make this linkage possible.

Networking is essential for generating and transferring ideas, knowledge and technologies and creates an environment suitable for embodying them into innovative processes and products. Also, networking justifies the creation of large-scale costly infrastructure which none of the stakeholders can afford and use independently in an effective way.

\section{The RIMPs ecosystem}

Research infrastructure is a crucial asset used within the process of creation of new scientific and, most importantly, technological (i.e. directed to a particular application) knowledge. The latter, in turn, is disseminated as an object of technology transfer in compliance with the Intellectual property rights (IPR) and builds competitive advantages by being embodied in innovative processes and 
A case which comprises all these features is the series of ASPERA-projects. Networking can be found at the very heart of ASPERA born by the convergence of particle physics, astrophysics and cosmology, and in the manner of governing and implementing the project (24 national funding agencies in Europe providing funding in astroparticle physics research); understanding of the new types of research infrastructure (so called "Magnificent Seven" consisting of the Cherenkov telescope array project which will detect cosmic high-energy gamma rays; $\mathrm{KM}_{3} \mathrm{NeT}$, a cubic-kilometre scale neutrino telescope that will be situated under the Mediterranean sea; ton-scale detectors to search out dark matter; a ton-scale detector to determine fundamental nature and mass of neutrinos; a megatonscale detector to investigate properties of neutrinos; a large telescope array to detect charged cosmic rays; and a third generational underground gravitational antenna, the total cost of which is estimated to be at least EUR 1 billion); funding their construction and maintenance (consortia of funding agencies from both inside and outside Europe); and conducting research by a range of research communities (2,000 scientists in some 50 or so laboratories). [24]

The rationale of the project states: "To look at the whole universe, astronomy needs large-scale advanced equipment which can only be built and operated through international collaboration. It is only by exploiting the intellectual potential of the whole European community that Europe will maintain its position at the forefront of astronomical endeavour." [25]

Box 2. ASPERA: Implementation of Astroparticle Physics European Coordination

The increase in the number of systemic studies of innovation activity at various management levels has been a clear-cut trend since the end of the 2oth century. The heightened interest in the application of the principles of systemic analysis in studying such an indefinite field as innovation is due to the complex character of this phenomenon - both in respect to the content and internal involvement of innovation processes, and in connection with the varied in power and direction of influence factors of the environment they reflect.

There are different interpretations of the concept of 'innovation system' (Dosi at all., 1988), (Freeman, Lundvall 1988), (Freeman, 1995), (Nelson, 1993), (OECD, 1997, 1999, 2002), but they all share a stress on the existence of nationally represented actors interacting in the process of generating technological knowledge and turning it into new/improved products/services and processes. These actors are above all private business enterprises, R\&D organizations and the human capital in them, but with the complication of innovation systems over the past decade - and particularly with the development of the concept of knowledge-based economy and society attention is also being increasingly paid to political institutions, financial and legal intermediaries, and so on, which determines the choice of environment factors and the groups of stakeholders which are subject of analysis below (Table 3 and Table 4).

Originally, the term ecosystem is used as a contraction of ecological system. Nowadays the concept of ecosystem has a range of applications, one of most recognizable in the field of innovation. The concept of 'innovation ecosystem' (Wessner, 2009), (Nachira, 2006) has been used with increasing frequency in scientific literature over the past few years. The reasons for that are several:

- Innovations do not occur in a vacuum - they depend on the environment in which they develop and with which they are organically bound;

Both the opportunities created and the potential damages should be managed at the introduction of innovation products and processes;

Innovations are not end in itself. They generate value for the individual consumers, growth and competitiveness for the national economies;

Innovation systems are not fixed in time. They evolve and develop in order to meet the new needs and circumstances.

At research of innovation systems, innovations are still perceived as a result of mechanical, somewhat linear processes, with easily measurable inflows and entirely predictable effects at the outcome. This also influences policies and the measures for their promotion mainly financing research projects, development of fundamental scientific fields, protection of intellectual property subjects.

Measures of this type are necessary as a basis for the generation and accumulation of new knowledge, but they are insufficient to encourage its polyvalent application into practice and multiplication of effect achieved.

The perception of national economies as innovations systems lends greater depth and complexity to the analysis. In this case, along with the familiar quantitative indicators for measuring incoming resources (investments and human capital) and results (patent and innovation activity), an attempt is made to cover the variety of interactions and the change in their intensity. The development of an innovation ecosystem requires transformations in several main directions (Figure 5).

Such an aspect of the analysis allows, at research of innovation systems, to lay the stress on the generation of value added for consumers, follow the dynamic changes of the market and the environment, and accelerate the transfer of knowledge in the direction of making it more concrete and introducing it into practice. An innovation ecosystem generates a new type of strategic assets whose source interactions under various forms are, and these in turn ensure long-term sustainable development and competitive advantages.

The lack of a generally accepted definition of R\&D is an important part of the concept itself, which stresses on the uniqueness of each innovation system depending on social, economic and political factors in a given temporal period. What is underscored as being of key importance for the understanding and application of the concept is the significance of the networks of connections and interaction between the actors when these networks are viewed as an overall system. 


\begin{tabular}{|l|l|}
\hline Linear innovation model & Dynamic business ecosystem \\
\hline Single disciplinary research & Multidisciplinary research \\
\hline Incremental innovation & Radical innovation \\
\hline Product functions & Value added for consumers \\
\hline Closed local research units & Global open innovation networks \\
\hline \begin{tabular}{|l|} 
Competitive advantages \\
Cumulative advantages
\end{tabular} \\
\hline $\begin{array}{l}\text { In this connection, the ecosystem perspective towards Ris is a point of view which } \\
\text { focuses the attention both on the interaction between a variety of stakeholders in terms } \\
\text { of Rl projects and the influence of different factors coming from the RIS environment. }\end{array}$ \\
\hline
\end{tabular}

Figure 5 Necessary changes for the development of an innovation ecosystem

products. Therefore, the necessity of construction and the impact of operation of RIs can be assessed only in the context of a research and innovation system.

The system approach in examining the potential of the nationally presented research centres and innovation companies, their activities and interaction is originally used at the end of the $20^{\text {th }}$ century (Nelson, 1992), (Metcalf, 1995), (Freeman, 1995), (Lundvall, 1998), (Lundvall, 2005), [26]. Due to the increasing complexity and dynamic changes of the contemporary globalised environment in the last decade the concept of "innovation system" has been developed, widened beyond the national borders and enriched as an "ecosystem perspective" to the whole chain of creation and adoption of new knowledge: science research and development - innovation.

In this connection, the ecosystem perspective towards RIs is a point of view which focuses the attention both on the interaction between a variety of stakeholders in terms of RI projects and the influence of different factors coming from the RIs environment.

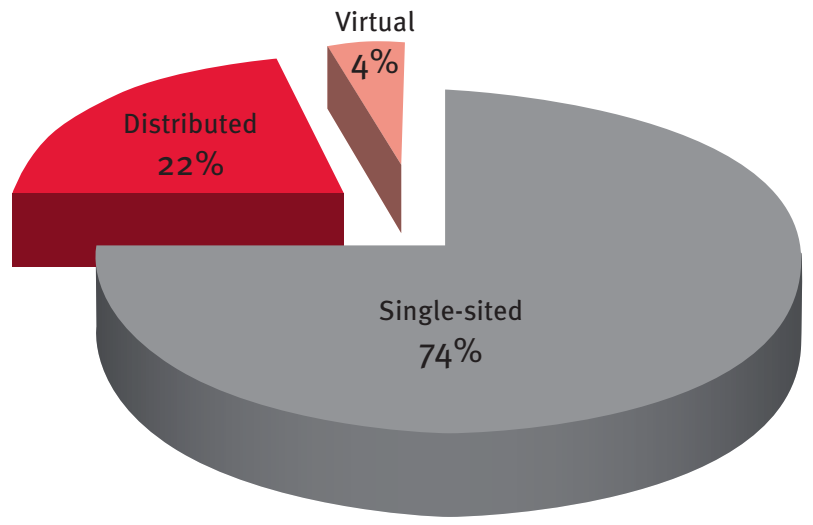

Figure 4 Research Infrastructure Megaprojects by location, \%
In line with the latest findings [27], [28] the ecosystem perspective to research infrastructure, which is placed at the heart of the research and innovation systems, allows a broader context of the study, including:

political, social, economic, technological, environmental dimensions;

a range of stakeholders, whose number and scope strongly vary depending on the location(s), sectoral specialisation and scientific communities involved;

- entrepreneurial spirit and innovation culture at all levels of decision making, which create a broad talent pool and innovation readiness/demand.

Taking into consideration all of the above, the RIMPs ecosystem can be defined as a dynamic framework of mutually influenced organisations and resources which ensure an alignment of the changing interests of different stakeholders in accordance with social and economic aims for sustainable growth. An approximation to the definition given above is presented at the Figure 1, where the main actors and interaction between them are comprised.

\section{RIMPs ecosystem: the environment}

Due to the scope of the RI and its panEuropean impact, the extensive amount of resources involved in it and wide public reflection of challenges addressed the RIs project management environment is replete with technological opportunities, social requirements, political controversies, regulatory and economic limitations. In circumstances like these the consensus of common priorities (including achieved by advanced exercises like foresight) and sound impact assessment of (likely) synchronised efforts involved and (likely) synergetic outcomes are of key importance. Bellow, the most significant issues concerning the dimensions of a project management environment are summarised:

> Political project environment Despite the fact the construction 


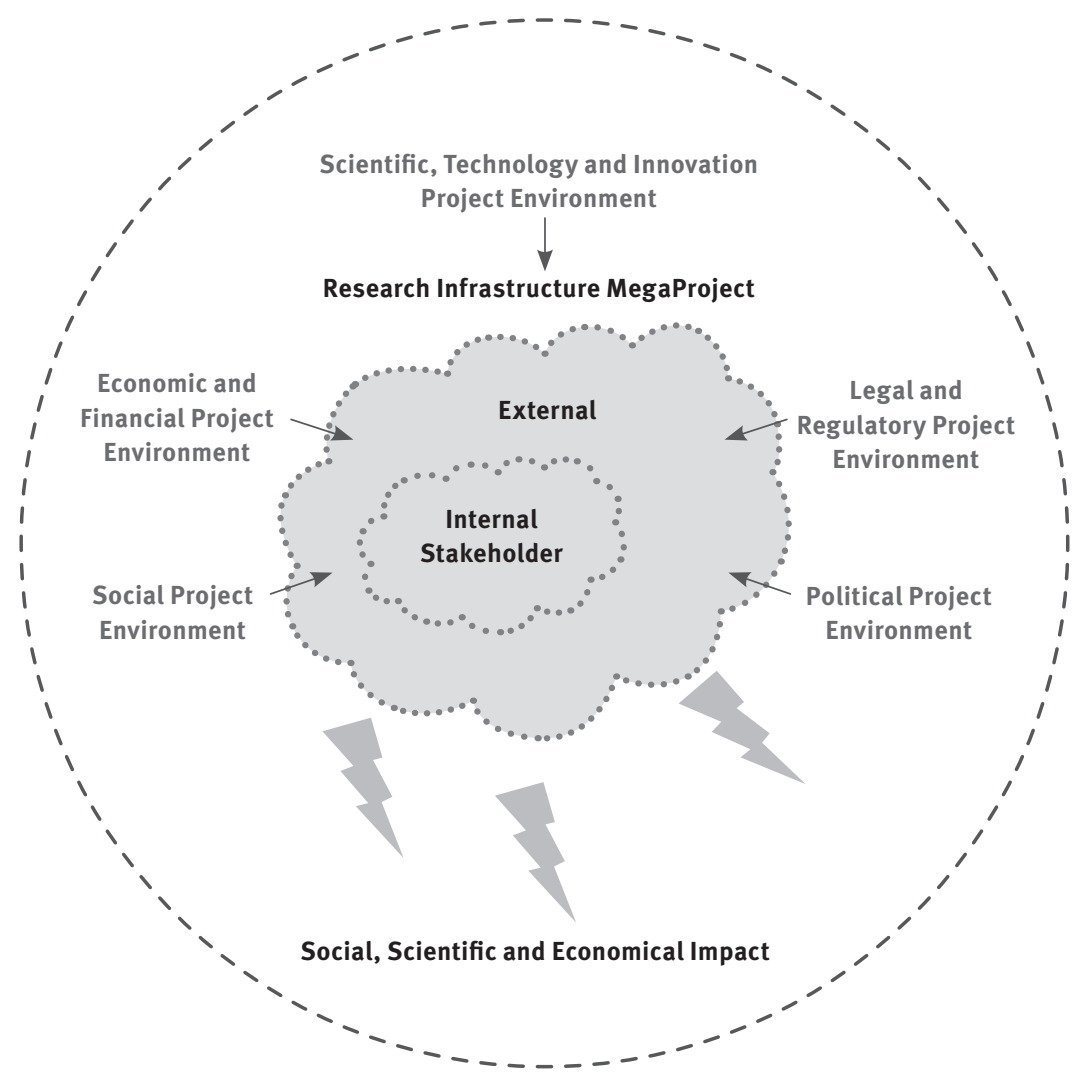

Figure 6 Research Infrastructure MegaProject's Ecosystem

and operation of RIs need detailed roadmaps and objective oriented programme instruments, the political will expressed by national policy documents and strategies for economic and social development is of key importance for their implementation in compliance with European and national regulations and good governance models. Otherwise, the lack of administrative capacity, the incompetency in bringing out priorities and pursuing targets, as well as the existence of bureaucratic hurdles and corruption practices provides a bad signal to the science community and create a business environment unfavourable to innovation.

\section{> Social Project environment}

The factors concerning the social environment affect bilaterally RIMPs. On the one hand, they are responsible for the existence of a talent pool of highly qualified and inspired specialists, able to learn continuously, familiar with contemporary technologies and their application in practice. On the other hand, search facility, technical performance requirements and the related technical and technological challenges; existence of competing and/or complementary facilities and planned ones; facility location(s) and local research and innovation system's potential; technology standards and technology dynamics in the field of RI operation.

- Legal and regulatory project environment (Europe, nationally and regionally)

Extremely complex is the RI project environment from legal and regulatory point of view. Apart from some details, the national legal frameworks of member states concerning scientific research are fully harmonised with European regulatory base. The most significant differences can be monitored in regard to specific measures for direct or indirect support of the innovation activity of nationally presented companies and their readiness for the adoption of new technologies.

Of particular interest are the following issues:

1. International standards in the field of project management and their implications on Megaprojects.

2. State aid for R\&D. Research and innovation activity as a well-recognised factor for knowledge based growth is an object of certain exceptions in European legislation. In order to reduce the administrative burden on public authorities and beneficiaries the European Commission has adopted the General Block Exemption Regulation (GBER) giving an automatic approval for a range of aid measures, including research and development, innovation, regional development, provision of risk capital and many others closely related to the process of decision making on design, location, construction and implementation of RIs. [29]

3. Public private partnerships. The complementary usage of private investments and European public funding, including Framework Programmes, 
is of prime importance not only for the development of particular science fields but also in order to assure favourable business environment for translating the results into innovative processes and products. The practice of developed economies proves that the fast, smooth and wide adoption of newly developed technologies creates competitive advantages and higher living standard (Pavitt, 1979). In this sense the early involvement of the private sector in research can guarantee long-term gain.

4. Public procurement and pre-commercial procurement. Through the procurement process and procedures the decisions on: a) the type of companies/consortia which are allowed to participate in a call for RI's management body (at the RIMP design phase), and b) the type of enterprises (e.g. SMEs, foreign companies, etc.) which are allowed to participate in a call for beneficiaries (at the RIMP implementation phase), are made. Pre-commercial procurement of innovation is intended to close the gap between Europe and its global competitors in spending in technological and innovation development by sharing the technological risk and favouring the interaction between the public authorities at different level (European, national, regional) and private sector in a more transparent and efficient way. [30, 31]

5. Intellectual property rights and technology transfer. The protection and empowerment of the intangible assets usage (patents, utility models, industrial design, trademarks, trade secrets, etc.) is a slippery territory even in cases where one company is concerned. The extended usage of ICT, intensive networking, multidisciplinary and the variety of partners involved in the process of new knowl- edge creation turn the task of fair distribution of benefits into a nearly impossible one.

In addition, a relatively recent ERIC regulation is aimed at supporting and harmonizing the conditions (status of RIs, tax liabilities, shared use of intellectual property rights) for initiating and incorporating collaborative projects of panEuropean interest.

Economic and financial project environment

As the construction and implementation of RIs require serious investment which exceed the financial capacity of national budgets on R\&D, the right mixture of dedicated to RIMPs funds from different sources (such as the Framework Programmes, including the Risk-Sharing Finance Facility (RSFF) instrument as part of $\mathrm{FP}_{7}$; Structural Funds; the European Investment Bank's financial instruments; new financial incentives developed under the Article 169 of the EU Treaty as

\begin{tabular}{|c|c|c|c|}
\hline Criteria & Scientific Communities & Intermediary Infrastructure & Business \\
\hline Mission & $\begin{array}{l}\text { Perform scientific research, } \\
\text { Strengthen research potential, } \\
\text { Encourage young scientists, } \\
\text { Allow human capital mobility, } \\
\text { Provide services }\end{array}$ & $\begin{array}{l}\text { Create a platform for co- } \\
\text { operation, Provide services, } \\
\text { consultancy and information, } \\
\text { Strengthen innovation potential, } \\
\text { Encourage private funding for } \\
\text { research and innovation }\end{array}$ & $\begin{array}{l}\text { Implement innovation activity, } \\
\text { Provide new and improved } \\
\text { processes and products, Take } \\
\text { part in technology transfer, } \\
\text { Favour the linkage between } \\
\text { science and market }\end{array}$ \\
\hline Project Objectives & $\begin{array}{l}\text { Develop new ideas, Create } \\
\text { new knowledge, Develop new } \\
\text { technologies }\end{array}$ & $\begin{array}{l}\text { Intensify interaction within the } \\
\text { research and innovation chain }\end{array}$ & $\begin{array}{l}\text { Embody new knowledge into new } \\
\text { and improved products }\end{array}$ \\
\hline Attitude to project & Strongly positive & Strongly positive & Strongly positive \\
\hline $\begin{array}{l}\text { Influence on } \\
\text { project }\end{array}$ & $\begin{array}{l}\text { As the research is in the very } \\
\text { heart of the project its results } \\
\text { predetermine the project success }\end{array}$ & $\begin{array}{l}\text { Influence on how intensive will be } \\
\text { the interaction between science } \\
\text { and business and thus on the level } \\
\text { of effectiveness and productivity } \\
\text { of project implementation }\end{array}$ & $\begin{array}{l}\text { Important influence rather on } \\
\text { dissemination and transfer of the } \\
\text { outcomes (new technologies and } \\
\text { products) than on direct results } \\
\text { (new ideas and knowledge) of the } \\
\text { project }\end{array}$ \\
\hline Impact of project & $\begin{array}{l}\text { Strongly influenced by objectives, } \\
\text { financing and partners } \\
\text { involvement, Cohesion in the field } \\
\text { of research infrastructure }\end{array}$ & Medium influenced & $\begin{array}{l}\text { Strongly influenced as the results } \\
\text { of innovation activity are the most } \\
\text { important source of competitive } \\
\text { advantages, Sustainable } \\
\text { knowledge based growth }\end{array}$ \\
\hline
\end{tabular}

Table 3 Main RI(M)P Stakeholders' Profile - Internal Stakeholders 
complementary measures to existing national and regional programmes; member states, private sector), is of prime importance for sustainable fulfilment of European and national RI road maps.

\section{RIMPs ecosystem: the}

\section{Stakeholders and Interaction}

The most highlighted feature of contemporary RIs is their openness and strong feasibility for shared facilities and transferable results. Bearing this in mind RIs can be considered as a focal point for bringing together a wide range of stakeholders depending on the pronounced multi-disciplinary of research and multifunctionality of services provided. Stakeholders can be gathered under two categories considering the implementation of a particular RIs project.

The group of internal stakeholders consists of actors and institutions that are established to and directly involved in the process of creation, transfer and/ or adoption of new knowledge. Representatives of this group are:

1. New knowledge providers - scientific communities (scientists, researchers, engineers and technicians from both public and private research centres and universities) working in a specific scientific domain, using research facilities in order to perform scientific research.

2. New knowledge users - multinationals, innovative companies, start-ups and entrepreneurs operating within a particular economic sector which embodied acquired technologies into innovative products.

3. Intermediary infrastructure - science and technology parks, innovation centres, virtual platforms, etc., which facilitate the interaction between the scientific community and business providing shared data bases, consultancy, physical and virtual space for co-operating.
The group of external stakeholders includes public authorities (decision makers, governance structures), funding organisations (European, national or regional funding agencies, venture capital) and social groups (e.g. in certain fields like education, health care, culture, leisure) as well as potential users of end results from the functioning of the research and innovation chain.

In addition, another key group has to be mentioned, namely the European Commission and other European institutions and bodies. The so called third stakeholder is responsible for vision-oriented complementary implementation of a range of RIs megaprojects, provision of an information platform for a dialog between the diversity of stakeholders and developing of a strategic coordination mechanism in order to ensure the effective management at a project, programme and pan-European level.

\begin{tabular}{|c|c|c|c|}
\hline Criteria & National/Regional Public Authorities & Financial Institutions/Instruments & Social Groups/End Users \\
\hline Mission & $\begin{array}{l}\text { Support science, technology } \\
\text { development and innovation, Create } \\
\text { favourable business environment, } \\
\text { Strengthen the national/regional } \\
\text { research system's capacity and } \\
\text { innovation potential of national/ } \\
\text { regional economy }\end{array}$ & $\begin{array}{l}\text { Funding science, technology } \\
\text { development and innovation, Provide } \\
\text { venture capital, Ensure favourable } \\
\text { conditions for business investment in } \\
\text { research and innovation, Encourage } \\
\text { private investments in innovation }\end{array}$ & $\begin{array}{l}\text { Provide talent pool, } \\
\text { Provide entrepreneurial } \\
\text { spirit and innovation } \\
\text { culture, Encourage } \\
\text { innovative end users, } \\
\text { Disseminate social } \\
\text { innovations }\end{array}$ \\
\hline Project Objectives & $\begin{array}{l}\text { Ensure regulatory framework, Provide } \\
\text { information and consultancy, Create } \\
\text { a platform for interaction, Support } \\
\text { public-private partnership, public } \\
\text { and pre-commercial procurement in a } \\
\text { transparent way }\end{array}$ & $\begin{array}{l}\text { Financing research and innovation } \\
\text { activity }\end{array}$ & $\begin{array}{l}\text { Not clear defined, long- } \\
\text { term oriented }\end{array}$ \\
\hline Attitude to project & Positive & Positive & Positive \\
\hline $\begin{array}{l}\text { Influence on } \\
\text { project }\end{array}$ & $\begin{array}{l}\text { May create serious enablers, } \\
\text { resp. disablers to foster or burden } \\
\text { successful project implementation }\end{array}$ & $\begin{array}{l}\text { May create serious enablers, } \\
\text { resp. disablers to foster or burden } \\
\text { successful project implementation }\end{array}$ & Not direct influence \\
\hline Impact of project & $\begin{array}{l}\text { Not directly influenced, long-term } \\
\text { oriented competitive advantages, } \\
\text { Economic cohesion, Sustainability of } \\
\text { economic growth }\end{array}$ & $\begin{array}{l}\text { Rather long-term than short-term } \\
\text { investment return }\end{array}$ & $\begin{array}{l}\text { Not directly influenced, } \\
\text { favour conditions for } \\
\text { long-term improvement of } \\
\text { quality of live and living } \\
\text { standard, Social cohesion }\end{array}$ \\
\hline
\end{tabular}




\section{Requirements for IRMPs management within a globalized and competitive environment}

Constantly expanding complexity and cost associated with RIMPs, together with their specificities mentioned above, need professional management and extensive expertise at every stage of their implementation. Pan-European importance and the objectives pursued by RIs (to overcome fragmentation at EU level; to close the gap in research and innovation potential; to address social, economic and environmental problems) further increase expectations in regard to effectively prioritising; creating the right profile of functionalities, services and access; developing and better exploiting the Rl's capacity.

Well-spread virtual networking patterns at all stages of design and implementation of RIMPs require in turn not less virtual or "cloud" management combined with flexible coordination between all the stakeholders (considering the dilemma on how to meet their very often conflicting interests), adaptive manner of putting into practice the accepted access policy and integration of various professional expertise depending on the particular science domain and location(s) in an ad-hoc way.

Flexible and forward-looking management of RIMPs need a range of analytical tools for assessment of the complex opportunities/treats related to the environment and strengths/weaknesses connected with the project characteristics (summarised in Table 5). To support decision-makers and RI managers in assessing driving forces and trends in the particular field, competitive advantages sources, value added reflexions and patterns and socio-economic impacts of RIs different forecasting technics and tools are developed (benchmarking, brainstorming, Delphi, expert panels, future workshops, key/critical technologies, roadmapping, scenarios, SWOT analysis, trends extrapolation, gap analysis, risk analysis, etc.). [32]
Despite the application of well-developed and widespread methodological tools it is difficult to define success in the case of RIMPs because of a number of reasons:

Despite the strategic framework and importance given to RIMPs in public debates, still only a small part of megaprojects in the field of research infrastructure are fully completed (Since the publication of the first roadmap in 2006 and its update in 2008, 10 projects of the 44 roadmap projects are in the implementation phase.)[33]. Most of them are at their preparatory phase or have not started.

- Research infrastructure is a background for performing scientific research, technology development and knowledge transfer. Assessment of the outcomes and evaluating the achieved level of effectiveness and productivity are a very tricky exercise due to the creative nature of research and innovation, significant risk and uncertainty associated with end results and the great variety of factors influencing on them.

- The most applicable methods for gathering information concerning the RIMPs impact include descriptive analyses and qualified data processing which do not allow an unambiguous appraisement of the satisfaction level of different societal groups as stakeholders. The OECD "Frascaty Family" manuals [34] are only a good starting point with many issues for interpretation.

As a result of these specific features of RIMPs and the established management practices some key challenges questioning the successful operation of RIs need to be outlined.

Despite the specific purpose and field of their implementation, large-scale RIs have to be managed rather by a professional team of project managers than by scientists and academic staff due to the different understanding of the tolerable level of technological, financial and market risk.
In the cases of distributed or virtual RIs, which combine the efforts of a great number of diversified stakeholders, imbalances in the research potential and/ or accepted practices/standards in performing scientific research may occur.

Dynamic changes in the fields of science and technology and newly emerging needs of society require a very flexible manner of prioritising the scientific domains, selecting of functions and services profile and appropriate placement, targeting a particular set of objectives. A need of up-dating the research agenda may arise at every stage of the project implementation.

The appropriate management approach has to consider specific functionalities of RIs, including: long-term sustainability; scientific excellence; ease of access to unique equipment and data bases; upgradeability; technology transfer; commitment, engagement and balanced participation of a wide range of internationally presented stakeholders; an efficiently functioning network of world-class facilities; strengthening the exploitation of new knowledge.

\section{Conclusions}

Large scale research infrastructures are a result of combined efforts of different institutions and require significant amount of resources and time. As such and regardless of their features they are considered as a scope of the basic principles and procedures of megaprojects. Moreover, the approaches used for the delivery, assessment and implementation of research infrastructure have to be aligned with ICCPM Strategic Planning Framework and Research and Innovation Strategy (as its central pillar), intended to provide a vital platform for combining the existing and new knowledge and practices in the field of MP and, as a result, creating a conceptual framework for enhancing the ability to manage complex projects, including RI.

Highlighting the RI projects profile, in turn, can provide lessons acceptable for common MP practice. 
Previous experience in the field of RIMP Effective usage of ICT

Right organisational structure/ management style Good understanding of vision/mission/strategic objectives of the project by all stakeholders

High level of alignment between project objectives and social needs

Ensured financing and partner involvement Appropriate risk assessment tools, etc.
Lack of experience in the field of RIMP

Lack of professional expertise

Misunderstanding about project objectives

Lack of financial resources

Lack of research capacity

Missing intermediary bodies

Insufficient business innovation potential

Partiality in achieving project objectives, etc.
Intensive public-private partnership Transparent practices of public procurement Widespread innovation culture Effectively working programme instruments Administrative capacity

Public acceptance and support, etc.
Unfavourable regulatory framework

Lack of venture capital

Lack of high-qualified human resources

Bureaucracy

Corruption practices

Lack of political support, etc.

\section{Table 5 Potential factors/barriers to support/impede the successful implementation of a RIMP}

The increasing expectations of society from the policy and decision-making in the field of RIMPs necessitate the extensive application of foresight methodology for assessing the future socio-economic impact at European, national and regional levels [35] and formulating of relevant strategies and policies for adequate management of RIs projects [36]. Foresight gives a comprehensive methodological framework and assures an open view for the possible directions of decision-making. Megaprojects as a whole, regardless of the particular field of their implementation, can be considered as an appropriate area for widening the application of such a methodology. Their essential features like large scale, huge funding and long-term orientation are reasonable grounds for that. In addition, a wider scope of their impact is more "below the radar" than "easy to monitor" which is another key precondition for preferring foresight technics to quantitative ones.

The majority of megaprojects in the field of research infrastructure are carried out as a series of relatively independent stages. The preparatory phase, which is a well-known practice in RIMPs, provides an opportunity of rethinking the project conception in terms of partner's involvement, resources allocation and budgeting, and improving the appropriate management technics including public procurement, public-private partnership, organisational schemes (vertical vs. horizontal), etc. In cases with serious public resonance and expectations like nuclear power plants, highways, etc., it would be reasonable to start the megaproject with small steps in order to better match the project objectives with long-term social needs and thus limit the social, economic and environmental risks of failure.

A specific characteristic of the projects is their closeness in terms of scope, time and resources allocated. It is woven into the very nature of work on a project basis and ensures the needed concentration on pursuing the planned objectives, respectively addressing the previously identified problems. Along with advantages, however, this approach imposes some constraints. The main among them is associated with the lack of interaction (information flows and transfer of best practices, lessons learned, competencies, knowledge and experience) between project teams as a result of different stakeholder groups involved. The application of management techniques (e.g. strategic thinking and visionary) at programme level combining the multi-project experience in a separate area allows continuity and further development on the basis of previous project achievements. This has to be a subject of research interest and, in turn, offered as guidelines, theoretical background and case studies for further improvement. For the purpose of conducting such empirical research, the formation of an extended data-base and the creation of a clear, concise and easy to apply methodological framework would be very timely.

\section{References}

Dosi, G., C. Freeman, R. Nelson, G. Silverberg and L. Soete (eds) (1988). Technical Change and Economic Theory, Pinter.

Goodridge, P., Haskel, J. and Wallis G. (2012), UK Innovation Index: Productivity and Growth in UK Industries, Nesta Working Paper 12/09, available at: www.nesta.org. uk/workingpapers_wp12-o9 (accessed 22 July 2012).

Gronli, M., Lilliestrale, A., Bredesen, A., Bolland, O., Barrio, M. and Rokke, N. (2011), “ECCSEL-European Carbon dioxide Capture 
and Storage Laboratory Infrastructure", Energy Procedia 4 (2011) 6168-6173, available at: www.elsevier.com/locate/ procedia (accessed 26 July 2012).

Favali, P., Beranzoli, L. (2009), “EMSO: European multidisciplinary seafloor observatory", Nuclear Instruments and Methods in Physics Research A 602 (2009) 21-27, available at: www.elsevier.com/ locate/nima (accessed 26 July 2012).

Freeman C. \& B-A. Lundvall (Ed.) 1988. Small Countries Facing the Technological Revolution, Pinter Publishers Ltd.

Freeman, C. (1995). The National System of Innovation in Historical Perspective, Cambridge Journal of Economics, No. 19, pp. 5-24; Lundvall, B.-Å. ed (1992). National Systems of Innovation: Toward a Theory of Innovation and Interactive Learning. Pinter Publishers Ltd.

Lundvall, B.-A. (1998), “Why study national systems and national styles of innovation?", Technology Analysis and Strategic Management, Vol. 10 No. 4, pp. 407-421.

Lundvall, B-A., (2005), “National Innovation Systems - Analytical Concept and Development Tool", Second version of paper to be presented at the DRUID-conference, June 27-June 29 , Copenhagen, Denmark, available at: http:// www.druid.dk/conferences/Summer2005/ Papers/Lundvall.pdf (accessed 30 July 2012).

Metcalf, J.S. (1995), “Technology systems and technology policy in an evolutionary framework", Cambridge Journal of Economics, Vol. 19 No. 1, pp. 25-46.

Nachira, F., (2006) The European Innovation Ecosystem Initiative for SMEs and Regional Development, ICEB and eBRF Conference, Tampere, available at: http://www.iccrinternational.org/eurocoop/docs/ws3/ nachira.pdf (accessed 18 September 2012).

Nelson, R. (ed.) (1993). National Innovation Systems. A Comparative Analysis. Oxford University Press, New York/Oxford.

Nelson, R.R. (1992), “National innovation systems: A retrospective on a study", Industrial and Corporate Change, Vol. 1 No. 2, pp. 347-374.

OECD. (2002). Dynamising National Innovation Systems. OECD Publications, Paris.

OECD. (1999). Managing National Innovation systems. OECD Publications. Paris.

OECD. (1997). National Innovation Systems, OECD Publications, Paris.
Spurio, M. (2012), “ $\mathrm{KM} 3 \mathrm{NeT:}$ Anunderwatermultikm3 neutrino detector”, Nuclear Instruments and Methods in Physics Research A, doi:10.1016/j.nima.2011.12.070, available at: www.elsevier.com/locate/nima (accessed 05 August 2012).

Pavitt, K. (1979), “Technical innovation and industrial development. The new causality”, Futures, Vol. 11 No. 6, pp. 458-470

Wessner, Ch., Entrepreneurship and the Innovation Ecosystem. Policy Lessons from the United States, Discussion Papers on Entrepreneurship, Growth and Public Policy, Chapter 5, Max-Planck Gesellschaft, Germany, available at: https://papers.econ. mpg.de/egp/discussionpapers/2004-46.pdf (accessed 18 September 2012).

\section{Footnotes}

[1] Innovation Union Scoreboard 2011, Research and Innovation Union Scoreboard, European Union, 2012, available at: http://www. proinno-europe.eu/metrics (accessed 22 July 2012).

[2] A vision for strengthening world-class research infrastructure in the ERA, Report of the Expert Group in Research Infrastructure, European Commission, DG Research, available at: http://ec.europa.eu/research/ infrastructures/pdf/era_100216.pdf (accessed 22 July 2012).

[3] http://www.riportal.eu/public/index. cfm?fuseaction=ri.search (accessed 14 September 2012).

[4] Report on Roadmapping of Large Research Infrastructures, OECD Global Science Forum, December 2008, available at: http://www. oecd.org/dataoecd/49/36/41929340.pdf (accessed 26 July 2012).

[5] http://ec.europa.eu/research/horizon2020/ index_en.cfm?pg=home\&video=none (accessed 25 July 2012).

[6] Europe 2020, A strategy for smart, sustainable and inclusive growth, Brussels, 3.3.2010, COM(2010) 2020 final, available at: http://eur-lex. europa.eu/LexUriServ/LexUriServ. do?uri=COM:2010:2020:FIN:EN:PDF (accessed 26 July 2012).

[7] Community legal framework for a European Research Infrastructure Consortium (ERIC), Council Regulation (EC) No 723/2009 of 25 June 2009, European Commission, DG Research, available at: http://ec.europa. eu/research/infrastructures/pdf/council regulation_eric.pdf (accessed 26 July 2012).

[8] http://cordis.europa.eu/fp7/home_en.html (accessed 25 July 2012).

[9] Green Paper, The European Research Area: New Perspectives, Brussels, 4.4.2007, $\operatorname{COM(2007)} 161$ final, available at http:// ec.europa.eu/research/era/pdf/era_gp_ final_en.pdf (accessed 25 July 2012).

[10] http://ec.europa.eu/research/ infrastructures/index_en.cfm?pg=esfriroadmap\&section=roadmap-2006 (accessed 25 July 2012).

[11] http://www.e-irg.eu/ (accessed 25 July 2012).

[12] http://ec.europa.eu/research/ infrastructures/index_en.cfm?pg=esfri (accessed 25 July 2012). 
[13] http://ec.europa.eu/research/fp6/index en.cfm (accessed 25 July 2012).

[14] Towards a European Research Area, Brussels,

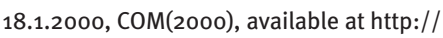
eur-lex.europa.eu/LexUriServ/LexUriServ. do?uri=COM:2000:0006:FIN:en:PDF (accessed 25 July 2012).

[15] Presidency conclusions, Lisbon European Council, 23 and 24 March 2000, available at http://www.europarl.europa.eu/summits/ lis1_en.htm (accessed 25 July 2012).

[16] http://www.cordis.europa.eu/fp5/home.html (accessed 25 July 2012).

[17] Training and mobility of researchers (19941998), Mid-term review of the access to large-scale facilities activity, Panel's MidTerm Review Report, European Commission, available at http://cordis.europa.eu/tmr/src/ midrev.htm (accessed 25 July 2012).

[18] http://europedia.moussis.eu/books/ Book_2/2/2/1/index.tkl?all=1\&pos=19 (accessed 25 July 2012).

[19] http://www.cordis.europa.eu/esprit/src/ intro.htm (accessed 25 July 2012).

[20] Enhancing access to research infrastructures, Improving the human research potential and the socio-economic knowledge base (19982002), Technical review manual, European Commission, 29 March 2002, available at http://cordis.europa.eu/improving/ infrastructure/techrev.htm (accessed 25 July 2012).

[21] Council Decision of 19 December 2006 on the specific programme: "Capacities" implementing the Seventh Framework Programme of the European Community for research, technological development and demonstration activities (2007 to 2013) (2006/974/EC), Official Journal of the European Union L 400 of 30 December 2006, available at: http://ec.europa.eu/research/ participants/portalplus/static/docs/calls/ fp7/common/29995-capacitiessp_en.pdf (accessed 22 July 2012).

[22] MEMORANDUM OF UNDERSTANDING, COST 4111/10, Brussels, 16 December 2010, available at: http://w3.cost.eu/fileadmin/ domain_files/TUD/Action_TU1003/mou/ TU1003-e.pdf (accessed 27 July 2012).

[23] Research and Innovation Strategy, International Centre for Complex Project Management, Version Date: March 2011, available at: http://www.iccpm.com/images/ stories/PDFs/Research/ICCPM_Research_
and_Innovation_Strategy_-_revised March_2011.pdf (accessed 27 July 2012).

[24] http://www.aspera-eu.org/index. php?option=com_frontpage \& Itemid $=43$ (accessed 14 July 2012).

[25] http://www.astronet-eu.org/ (accessed 14 July 2012).

[26] National Innovation Systems, OECD, 1997, available at: http://www.oecd.org/ dataoecd/35/56/2101733.pdf (accessed 30 July 2012).

[27] http://www.innovation-ecosystems.org/ (accessed 30 July 2012).

[28] The Role of the National Science Foundation in the Innovation Ecosystem, NSF Directorate for Engineering, version 08/25/2010, available at: http://www.nsf.gov/eng/iip/ innovation.pdf (accessed 30 July 2012).

[29] Commission Regulation (EC) No 800/2008 of 6 August 2008 declaring certain categories of aid compatible with the common market in application of Articles 87 and 88 of the Treaty (General block exemption Regulation), available at: http:// eur-lex.europa.eu/LexUriServ/LexUriServ. do?uri=CELEX:32008Ro800:EN:NOT (accessed 31 July 2012).

[30] Pre-commercial Procurement of Innovation. A missing link in the European innovation cycle, March 2006, available at: ftp://ftp. cordis.europa.eu/pub/fp7/ict/docs/pcp/ precommercial-procurement-of-innovation_ en.pdf (accessed 02 August 2012).

[31] Pre-commercial Procurement: Driving innovation to ensure sustainable high quality public services in Europe, Brussels, 14.12.2007, $\operatorname{COM(2007)} 799$ final, available at: http://ec.europa.eu/invest-in-research/pdf/ download_en/com_2007_799.pdf (accessed 02 August 2012).

[32] Mapping Foresight. Revealing how Europe and other world regions navigate into the future, European Foresight Monitoring Network, European Commission, November 2009, available at: http://ec.europa.eu/ research/social-sciences/pdf/efmn-mappingforesight_en.pdf (accessed 6 August 2012).

[33] Strategy Report on Research Infrastructures, Roadmap 2010, ESFRI, European Union, 2011, available at: http://ec.europa.eu/research/ infrastructures/pdf/esfri-strategy_report_ and_roadmap.pdf (accessed 6 August 2012).

[34] Frascati Manual. Proposed standard practice for surveys on research and experimental development, OECD, 2002, available at: http://www.uis.unesco.org/Library/ Documents/OECDFrascatiManualo2_en.pdf (accessed 06 August 2012).

[35] An initiative of the project Research Infrastructure: Foresight and Impact (RIFI) (http://www.rifi-project.eu) is the on-line tool FenRIAM (Foresight enriched Research Infrastructure Impact Assessment Methodology, http://www.fenriam.eu) designed as a framework for socio-economic impact assessment of RIs of pan-European significance. The project was financed under $\mathrm{FP}_{7}$ and was implemented by a Consortium made up of 13 partners from 4 countries, including the Applied Research and Communication Fund (www.arcfund.net).

[36] ForeIntegra-RI Project (Integrating Foresight in Research Infrastructures Policy Formulation), finances under FP6 and coordinated by the Applied Research and Communication Fund (http://www.arcfund. net/Foreintegra/docs/Forelntegra $\% 20$ Policy\%2oRecommendations.pdf) 